ACERCA DE LA LEGALIDAD DE LA GUERRA DE IRAK

\title{
LA SUPUESTA LEGALIDAD DE LA REANUDACIÓN DE LA GUERRA EN IRAK. RÉPLICA A UNA DEFENSA DE LA POSICIÓN DE JOSÉ MARÍA AZNAR
}

José Luis VALlarta MARróN*

SUMARIO: I. Introducción. II. Los incumplimientos de Irak. III. El marco normativo. IV. La violación del alto el fuego y la paz y seguridad de la región como justificaciones de la invasión. V. Rechazo de la tesis de la ilegalidad de la guerra por la exigencia de una nueva resolución. VI. Tesis de la legalidad de la guerra sin necesidad de una nueva resolución del Consejo de Seguridad. VII. Conclusiones de los autores. VIII. Réplica o antitesis del autor del presente artículo. IX. Conclusiones.

\section{INTRODUCCIÓN}

El Instituto de Investigaciones Jurídicas de la UNAM publicó en el Anuario Mexicano de Derecho Internacional ${ }^{1}$ varios artículos relativos a la invasión de Irak, llevada a cabo en marzo de 2003, por Estados Unidos de América (EUA) y aliados con el apoyo de España. Dicho instituto respondió así a la necesidad de analizar, desde un punto de vista jurídico, los eventos que han provocado reacciones diversas en el mundo académico.

Con apego a la lógica exigencia de exponer diversos puntos de vista para llevar a cabo una investigación objetiva, y sin suscribir posición alguna de las allí expresadas, se incluyeron en el volumen correspondiente del anuario mencionado opiniones de autores de varias tendencias, incluidos españoles defensores a ultranza de la posición de los invasores y del entonces presidente del gobierno de España, José María Aznar.

* Maestro de derecho internacional público en la Facultad de Derecho de la UNAM y en la Universidad Iberoamericana. Embajador de México (jubilado).

1 Anuario Mexicano de Derecho Internacional, México, UNAM, Instituto de Investigaciones Jurídicas, vol. IV, 2004, pp. 67-86. 
Cuando un jurista está al servicio de su gobierno o en defensa de un cliente, es ético que su argumentación vaya encaminada a la defensa de una posición previamente determinada, dentro de ciertos límites éticos y doctrinales. Es frecuente que los gobiernos adopten posiciones y actúen utilizando criterios meta jurídicos en aras de la defensa de un supuesto interés nacional, no siempre legítimo o, peor aún, en defensa de posiciones partidistas o personales lejanas a la legalidad; en esas situaciones, el papel de los asesores jurídicos suele reducirse a la búsqueda de argumentos en apoyo de tesis políticas, no necesariamente apegadas a la norma jurídica. Lamentablemente, en ese empeño, muchos juristas abandonan la ética y la ortodoxia y deforman el derecho para acomodar intereses gubernamentales. Esa función de asesoría jurídica gubernamental es necesaria y todos los gobiernos recurren a ella; no es válido reprochar a servidores públicos y consultores gubernamentales por seguir la línea dada por la autoridad a la que sirven y deben lealtad, si bien ese esfuerzo por apoyar en derecho esa línea, tiene tanto límites científicos o teóricos como morales. Por otra parte, el medio académico tiene el derecho de ver con desconfianza toda tesis jurídica concebida por académicos o funcionarios públicos para justificar posiciones oficiales.

Tenemos justo título para esperar del catedrático y del investigador independientes un esfuerzo auténtico por expresar, frente a un acontecimiento internacional, lo que el derecho prescribe; como el juez, el académico y el investigador tienen el deber de subsumir el caso a la norma aplicable. Por ello, no deja de sorprender que catedráticos apliquen su talento para coincidir en sus opiniones con posiciones oficiales; si el catedrático, además de servir a la academia sirve al gobierno, se coloca indebidamente en un conflicto de intereses. Los lectores seguramente tienen en mente a juristas, sobre todo de las grandes potencias, cuyas posiciones, a pesar de la ciencia patente en sus escritos, tienen una sorprendente coincidencia con la política exterior de sus gobiernos. Invito a los lectores a que analicemos el artículo de los catedráticos de las Universidades españolas de León y de Santiago de Compostela, señores Romualdo Bermejo García y Carlos Ruiz Miguel (en adelante "los autores"), publicado en el anuario citado, con la mira de evaluar su objetividad y formular nuestras propias conclusiones. El análisis de la argumentación de los autores, tiene la ventaja de que ésta coincide en todo con la defensa oficial de las potencias que invadieron Irak en marzo de 2003; por tanto, nuestro 
análisis será también de la argumentación oficial, cuya compatibilidad con el derecho internacional, desde ahora ponemos en duda.

\section{LOS INCUMPLIMIENTOS DE IRAK}

Con buena lógica, los autores parten de una premisa que ya no requiere comprobación: el hecho de que Irak violó reiterada y tozudamente obligaciones internacionales que el Consejo de Seguridad de la Organización de las Naciones Unidas (ONU) le impuso en el ejercicio de sus atribuciones; proceden enseguida a considerar si el tenor de la Resolución 1441 del consejo, aunada a las múltiples resoluciones adoptadas desde la criminal invasión de Kuwait por Irak, hacían necesaria una nueva resolución que expresamente autorizara el ataque armado que analizamos. ${ }^{2}$ Asimismo, los autores reflexionan sobre si la invasión de marzo puede calificarse de lícita en virtud de otros argumentos jurídicos, a la luz de los propósitos de la ONU o del derecho inmanente a la legítima defensa, reconocido por la carta de la organización.

\section{EL MARCO NORMATIVO}

Proceden los autores a exponer el marco normativo aplicable y su interpretación; nos recuerdan que, tras la invasión de Kuwait por Irak, el Consejo de Seguridad adoptó una serie de resoluciones hasta llegar a la 1441, que es la que incorporó el párrafo en el que se amenazó a Irak con que, de seguir infringiendo sus obligaciones, se expondría a "graves consecuencias". Los autores afirman que la legalidad de la invasión debe analizarse mediante estudio de todas las resoluciones pertinentes, a la luz de la Carta de la ONU, con lo cual estamos de acuerdo; proceden a continuación a recordarnos la esencia de las más relevantes resoluciones en los términos que resumimos a continuación:

- La Resolución 660 (1990) condenó la invasión y ordenó a Irak que se retirara de Kuwait.

2 Las opiniones y afirmaciones de los autores se expresan mediante resúmenes o paráfrasis hechos por el autor del presente trabajo; cuando se recurre a transcripciones, éstas se incorporan con letra cursiva. 
- La Resolución 661 (1990) impuso sanciones a Irak, sin autorizar el uso de la fuerza, la cual, nos dicen con tino los autores, se hubiera podido usar en esa instancia sin necesidad de autorización del Consejo de Seguridad, pues desde el ataque armado de Irak y la consiguiente invasión de Kuwait, en todo momento este último Estado tuvo el derecho inmanente a la legítima defensa individual o colectiva; era claro que Kuwait no podía resistir solo la superioridad bélica iraquí y que deseaba ese apoyo colectivo que varios Estados estaban ya dispuestos a dar.

- La Resolución 678 (1990) autorizó a los Estados miembros a hacer uso de "todos los medios necesarios" para hacer cumplir la Resolución 660 (o sea para que Irak se retirara de Kuwait) y para "restaurar la paz y la seguridad en la región". Sugerimos al lector que tenga en mente la última frase entrecomillada, pues la misma, de aparente nobleza y coincidencia con los más altos propósitos de la ONU, fue el instrumento dialéctico de los autores y otros juristas para intentar justificar la invasión.

- La Resolución 687 (1991) exigió a Irak la eliminación de armas de destrucción masiva; la supresión de programas de armas químicas, biológicas o nucleares; su abstención de apoyar a grupos terroristas y la aceptación de esas condiciones para la entrada en vigor de un "alto el fuego".

\section{LA VIOLACIÓN DEL ALTO EL FUEGO Y LA PAZ Y SEGURIDAD DE LA REGIÓN COMO JUSTIFICACIONES DE LA INVASIÓN}

En el texto de la Resolución 678, encontramos el argumento principal de los autores en pro de la legalidad de la invasión de marzo de 2003; atraen ellos nuestra atención al hecho de que esa resolución autorizó el uso de la fuerza, no sólo para lograr la retirada de Irak allende las fronteras de Kuwait, sino también para lograr "el restablecimiento de la paz y la seguridad en la región". Los autores nos recuerdan en su argumentación que la resolución comentada estableció un "alto el fuego" que, como toda tregua de esa naturaleza, no puso fin definitivamente a las hostilidades. Efectivamente, ese armisticio o paz provisional fue condicionado por el Consejo de Seguridad de la ONU al cumplimiento por Irak de ciertos requisitos específicos, entre ellos, la notificación por Irak 
al secretario general y al Consejo de Seguridad de su aceptación de las disposiciones y condiciones para el "alto el fuego" establecido por el Consejo de Seguridad en la Resolución 687. Mediante una comunicación del 6 de abril de 1991, el representante permanente de Irak transmitió al presidente en turno del Consejo de Seguridad una carta de su ministro de Relaciones Exteriores en la que se notificó oficialmente la aceptación por Irak, irrevocable y sin condiciones, de la Resolución 687; así, en esa fecha, entró en vigor el acuerdo de "alto el fuego", en los términos fijados por el Consejo de Seguridad. ${ }^{3}$

Nos recuerdan los autores una norma del derecho internacional clásico, según la cual, cuando uno de los beligerantes rompe las condiciones del "alto el fuego", la parte ofendida por ese incumplimiento, deja de estar obligada por el acuerdo respectivo y, en consecuencia, puede reanudar las hostilidades; por otra parte, llevan nuestra atención a la Resolución 1441 (2002) del Consejo de Seguridad, en la que ese órgano principal de la ONU da fe de que Irak "ha incurrido y sigue incurriendo en violación grave de sus obligaciones" con arreglo a las resoluciones en la materia, entre ellas la Resolución 687. Recordemos con los autores que fue la Resolución 1441, con la que el propio consejo advirtió a Irak que, de seguir infringiendo sus obligaciones, se expondría a "graves consecuencias".

Concluyen los autores que: a) Si la defensa de Kuwait fue autorizada por el Consejo de Seguridad; b) Si las hostilidades consecuencia de esa agresión y defensa fueron suspendidas por un acuerdo de "alto el fuego"; c) Si Irak violó las condiciones del "alto el fuego"; d) Luego entonces, la autorización de atacar a Irak, suspendida por el "alto el fuego", se reactivó automáticamente, en virtud del derecho internacional, y por tanto, los invasores actuaron conforme a derecho.

Podemos confirmar que el convenio (II) relativo a las leyes y usos de la guerra terrestre y su anexo: reglamento sobre las leyes y usos de guerra terrestre, firmado en La Haya, el 29 de julio de 1899, en el artículo 40 del reglamento dispone: "Toda violación grave en el armisticio cometida por una de las partes, da a la otra el derecho a denunciarlo, y hasta en

3 Véase Resolución 689 (1991), del 9 de abril de 1991, del Consejo de Seguridad de la ONU y las decisiones del consejo publicadas junto con esa resolución, en las que se transcribe la carta en cuestión. 
caso de urgencia el de romper de nuevo las hostilidades inmediatamente". 4

Más adelante, en nuestra réplica a la argumentación de los autores, analizaremos la aplicabilidad de esa disposición del siglo XIX al "alto el fuego" concertado en el Consejo de Seguridad de la ONU.

Acto seguido los autores nos invitan a leer las resoluciones del Consejo de Seguridad en el marco de la Carta de las Naciones Unidas y afirman que la misma "no prohíbe la guerra de manera absoluta y que tiene como objetivo el impedir la misma "en la mayor medida posible"; también traen a colación las conocidas dos excepciones a la prohibición de recurrir a la fuerza armada, a saber: las atribuciones del Consejo de Seguridad para ejercerla (o autorizarla, según interpretaciones recientes que ha aceptado en buen grado la comunidad internacional) y la legítima defensa reconocida en el artículo 51 de la Carta de la ONU.

Los autores mencionan una tercera excepción no incluida en la carta: el uso de la fuerza armada por causas humanitarias si el Consejo de Seguridad no actúa. ${ }^{5}$

4 Véase Méndez Silva, Ricardo y López Ortiz, Liliana (comps.), Derecho de los conflictos armados. Compilación de instrumentos internacionales, regionales y otros textos relacionados, México, UNAM-CICR, 2003, t. I, p. 37.

5 En relación con el tema de la prohibición del uso de la fuerza armada por los Estados, incorporada en la Carta de la ONU y las excepciones a esa prohibición según la propia carta, pueden consultarse, entre otros, los siguientes autores y textos: Arellano García, Carlos, Segundo curso de derecho internacional público, 2a. ed, México, Porrúa, 1998, pp. 432-491; Brotóns, Antonio Remiro, Derecho internacional, Madrid, McGraw-Hill, 1997 (capítulos XXXIII y XXXIV: "La prohibición de la amenaza y el uso de la fuerza armada en las relaciones internacionales" y "El sistema de seguridad colectiva"), pp. 907-984; Bourquin, Maurice, L'Etat Souverain et L'Organization Internationale, New York, Manhattan Publishing Company, 1959, pp. 80-91; Brierly, J. L., La ley de las naciones. Introducción al derecho internacional de la paz, México, Editora Nacional, 1950 (cap. IX: "El derecho internacional y el recurso a la fuerza"), pp. 227-240; Carter, Barry E. y Trimble, Phillip R., International Law. Use of force and arms control, 3a.ed., New York, Aspen Law \& Bussines, 1999, pp. 1145-1162; Castañeda, Jorge, "La prohibición del uso de la fuerza", Obras completas, t. III: Política exterior y cuestiones internacionales, México, Secretaría de Relaciones Exteriores, Instituto Matías Romero de Estudios Diplomáticos-El Colegio de México, 1995, p. 324; Cassese, Antonio, International Law, New York, Oxford University Press, 2001, pp. 296-299; Decaux, Emmanuel, Droit International Public, L'interdiction du recours a la force, 3a ed., París, Editions Dalloz, 2002, pp. 243-249; Gros Espiell, Héctor, "La pretendida legítima defensa preventiva y la guerra en Iraq", Anuario Mexicano de Derecho Internacional, vol. IV, 2004, pp. 189-204; Gutiérrez Espada, Cesáreo, Derecho internacional público, Madrid, Trotta, 1995, pp. 41-48; López-Bassols, Hermilo, Derecho internacional público contemporáneo, México, Porrúa, 2001, pp. 123-138. Méndez Silva, Ricardo, "Fuerza militar internacional", Diccionario de derecho internacional, México, Porrúa-UNAM, 2001, pp. 177-178; Nguyen Quoc Dinh, Daillier, Patrick et Pellet, Alain, Droit International Publi., Mantiende la paix et de la securité internationales, 7a. ed., París, LGDJ, 2002, pp. 989-1040; Ortiz Ahlf, Loretta, Derecho 
En el artículo comentado, los autores reiteran que la Resolución 678 (1990) autorizó a los Estados miembros "el uso de todos los medios necesarios" para conseguir dos fines: primero, "hacer cumplir la Resolución 660" (o sea, la retirada de Irak) y, segundo, "para restaurar la paz y la seguridad en el área"; a continuación nos recuerdan que el primer fin se logró mediante la operación "tormenta del desierto", y que, expulsado Irak de Kuwait, quedaba por lograrse el segundo fin, a saber: "restaurar la paz y la seguridad en la región", el cual, nos dicen, no sería logrado mientras Irak se abstuviese de cumplir cabalmente las condiciones impuestas por el Consejo de Seguridad.

Llegamos a lo que parece ser otro de los argumentos principales de los autores, quienes razonan de la siguiente manera: el incumplimiento por Irak de las condiciones impuestas por el Consejo de Seguridad para el establecimiento y mantenimiento del "alto el fuego" dio fin a esa tregua y reactivó la autorización para "el uso de todos los medios necesarios para ...restaurar la paz y la seguridad en el área"; por tanto, concluyen, la reanudación de hostilidades por las partes agraviadas por la violación, hasta llegar a la invasión de Irak y el derrocamiento de Sadam Hussein, fue acorde con el derecho internacional por la aplicación de las reglas relativas a la práctica de los Estados en materia de violaciones al "alto el fuego" y por la reactivación automática de la autorización dada

internacional público, 2a. ed., México, Oxford University Press, 2002; Pastor Ridruejo, José A., Curso de derecho internacional público y organizaciones internacionales, 8a. ed., Madrid, Tecnos, 2002; El mantenimiento de la paz y seguridad internacionales, cit., pp. 738-745. Rodríguez Carrión, Alejandro, Lecciones de derecho internacional público, 4a. ed., Madrid, Tecnos, 2001; Lección 23 a. El control del uso de la fuerza, cit., pp. 583-617; Sepúlveda, Cesar, El derecho de gentes y la organización internacional en los umbrales del siglo XXI. La Carta de las Naciones Unidas y su contenido jurídico, México, UNAM-FCE, pp. 124-154; Shaw, Malcolm N., International Law, International Law and the use of force by States, 4a. ed., UK, Cambridge University Press, 1997, pp. 777-823; Skubiszewsky, K.J., "Uso de la fuerza por parte de los Estados, seguridad colectiva, derecho de guerra y neutralidad", Sorensen, Max (ed.), Manual de derecho internacional público, México, FCE, 2000, pp. 691-732. Vallarta Marrón, José Luis, "El derecho internacional aplicable a la ocupación militar de Irak por Estados Unidos de América y el Reino Unido de la Gran Bretaña e Irlanda del Norte", El Foro, México, Barra Mexicana, Colegio de Abogados, XIII época, t. XVI, núm. 1, 1er. semestre, 2003, pp. 169-185. Resolución 2625 (XXV0 de la AGNU; Declaración sobre los Principios de Derecho Internacional referentes a las relaciones de amistad y a la cooperación entre los Estados de conformidad con la Carta de las Naciones Unidas. Resolución 3314 (XXIX) de la AGNU: definición de la agresión. Resolución 42/22 de la AGNU: Declaración sobre el mejoramiento de la eficacia del principio de la abstención de la amenaza o de la utilización de la fuerza en las relaciones internacionales. Corte Internacional de Justicia. Asunto de las actividades militares y paramilitares en Nicaragua y contra ésta (Nicaragua c. Estados Unidos de América). Sentencia del 27 de junio de 1986 [CIJ Recueil, 1986, pp. 102-105.] 
por la Resolución 678 para: a) Forzar la retirada de Irak (objetivo logrado) y b) Restaurar la paz y la seguridad en la región (objetivo, según ellos, por ser alcanzado).

Proceden los autores a hacer un recuento de las veces en que en la Resolución 1441, que amenazó con las "graves consecuencias", se citan tanto la Resolución 660, que ordenó la retirada de Kuwait, como la 687, que estableció las condiciones del "alto el fuego". Sin duda alguna, ese recuento afirma algo indiscutible, esto es, la relación existente entre todas las resoluciones del Consejo de Seguridad sobre el tema y la necesidad de tomarlas en cuenta en su conjunto para una correcta interpretación.

Para los autores, la correcta interpretación se encuentra en la respuesta a la pregunta: ¿cuáles serían las "graves consecuencias"?; para ellos, la contestación estaría relacionada con la Resolución 687, o sea, en la ruptura del alto el fuego y, por tanto, en la reanudación "lícita" de la guerra. Aceptan los autores que puede argumentarse que tal vez el restablecimiento de la paz y la seguridad regionales se hubiera podido lograr con medidas coercitivas que no implicaran el uso de la fuerza armada, pero rechazan categóricamente que la invasión haya sido ilegal; al respecto, nos hacen ver que las tesis por ellos defendidas fueron las esgrimidas por Estados Unidos de América y aliados en la Declaración sobre Irak de las Azores, ${ }^{6}$ previa a la invasión de marzo de 2003.

\section{RECHAZO DE LA TESIS DE LA ILEGALIDAD DE LA GUERRA POR LA EXIGENCIA DE UNA NUEVA RESOLUCIÓN}

A continuación, los autores examinan y rechazan la tesis de la ilegalidad de la guerra por la exigencia de una nueva resolución que autorizara expresamente el uso de la fuerza después de la amenaza incorporada en la Resolución 1441; en un aparente fair play, exponen los argumentos siguientes contrarios a las tesis por ellos sostenidas: primero, la violación de la Resolución 1441, tendría que ser declarada por una nueva resolución del Consejo de Seguridad, y segundo, que las "graves consecuencias", con las que se amenazó a Irak, tendrían que ser expresamente determinadas en esa nueva resolución. 
En cuanto al argumento de la necesidad de una nueva evaluación por el Consejo de Seguridad, los autores recuerdan que ese consejo, reunido el 27 de enero de 2003, recibió un informe del jefe de inspectores de la ONU, el doctor Hans Blix, en el que se enumeraron incumplimientos de Irak y trabas a la función de los inspectores, los cuales mostraron que Irak estaba muy lejos de haber acatado de manera irrestricta e incondicional las exigencias impuestas por el consejo. ${ }^{7}$

Por lo que se refiere al segundo argumento que los autores citan como contrario a sus tesis, aducen que la interpretación de sus oponentes, misma que califican de literal por exigir la determinación expresa de las "graves consecuencias", se halla aquejada de numerosas debilidades, a saber: el tenor de la Resolución 1441 indica que el Consejo de Seguridad dio a Irak la "última oportunidad" para detener las "graves consecuencias"; el informe de los inspectores confirmó las violaciones por Irak, de donde, concluyen, al violarse las condiciones del "alto el fuego", la guerra suspendida podría reanudarse; por otra parte, advierten que, de haber sido necesaria una nueva resolución, se hubiera podido producir una situación de parálisis en el Consejo de Seguridad (por los vetos anunciados o vaticinados), lo cual hubiera, dicen ellos, vaciado de contenido a todas las resoluciones anteriores.

Por otra parte, los autores reprochan a quienes aducen la ilegalidad de la invasión su mutismo por el despliegue de fuerzas anterior a la invasión y preguntan: “¿Cómo se puede aceptar ese inmenso despliegue militar, cuyos efectos ahora se pueden ver claramente, y condenar la intervención? ¿Acaso ese despliegue no representaba una amenaza de uso de la fuerza que en teoría estaría prohibida por el párrafo 4, del artículo 2, de la carta?". ${ }^{8}$

\section{TESIS DE LA LEGALIDAD DE LA GUERRA SIN NECESIDAD DE UNA NUEVA RESOLUCIÓN DEL CONSEJO DE SEGURIDAD}

En su análisis, los autores vuelven a exponer y a desarrollar la tesis de la legalidad de la guerra sin necesidad de una nueva resolución que determinara el alcance de la expresión "graves consecuencias" y que au-

7 El informe del jefe de inspectores, Hans Blix, es citado y transcrito parcialmente por los autores, Anuario..., cit., p. 78.

8 Véase Anuario..., cit., p. 80. 
torizara expresamente el uso de la fuerza armada. Veremos después en nuestra réplica (infra, sección VIII) si su reiteración de argumentos es convincente.

Recuerdan los autores que una de las tesis que rechazan la necesidad de una nueva resolución se basa en: a) La defensa de los Principios de las Naciones Unidas, y b) La legítima defensa preventiva; aclaran que esos argumentos se estudian de forma hipotética en virtud de que no ha sido la defensa oficial de Estados Unidos de América y sus aliados respecto de la guerra.

Afirman esos catedráticos que se ha sostenido que es posible una intervención militar, aún sin estar prevista expresamente en resolución alguna del Consejo de Seguridad, siempre y cuando aquélla se haga para defender los principios consagrados en la Carta de las Naciones Unidas; al respecto citan el precedente de los bombardeos en la antigua Yugoslavia por la Organización del Tratado del Atlántico del Norte (OTAN) en 1999. Haciendo teoría sobre ese precedente, los autores, con alguna cautela, debido a la indudable controversia de su afirmación, sostienen que nos encontramos ante un tercer tipo de guerra (los anteriores serían la legítima defensa y la acción militar por el Consejo de Seguridad o con su autorización); para exponerla, usan un criterio teleológico o finalista como contrapartida a una interpretación de la Carta de la ONU que ellos califican de literal o sistemática; sostienen que hoy en día, las violaciones masivas y flagrantes a los derechos humanos fundamentales o al derecho internacional humanitario aplicable a los conflictos armados, podrían justificar acciones armadas, como se puso de manifiesto en el caso de Kosovo; reconocen que no se puede hablar de una costumbre internacional que ampare las intervenciones humanitarias sin autorización del Consejo de Seguridad, aunque algunos, nos dicen, detectan una norma jurídica in statu nascendi.

Recuerdan los autores que los Estados Unidos de América empezaron a construir una argumentación alternativa al uso de la fuerza previa autorización del Consejo de Seguridad; se refieren a la "legítima defensa preventiva" que va mucho más allá de la condición restrictiva que impuso la Carta de la ONU al reconocer el derecho inmanente a la legítima defensa individual o colectiva "en caso de ataque armado"; 9 parecen los

9 Véase Rice, Condolezza, Corriere della Sera, 8 de noviembre de 2002, citada por Gros Espiell, Héctor, Anuario..., cit., p. 191. 
autores sostener la tesis estadounidense al afirmar que esa tesis trataría de dar un nuevo sentido a la legítima defensa de acuerdo con la realidad social contemporánea; a continuación traen a colación el precedente de la defensa llevada a cabo por Israel durante la guerra de los seis días.

Los autores ven considerables ventajas en una interpretación amplia de la noción de la legítima defensa incorporada en la Carta de la ONU, pues aducen que el Estado que se ampara en esa institución para la protección de su integridad territorial, soberanía e independencia, es el único juez de la situación, dicho en otras palabras, puede actuar a su antojo; por otra parte, destacan las dificultades que encontraría un Estado que considere necesario hacer uso de la fuerza contra otro para vencer las complicaciones político jurídicas y eventuales vetos en el Consejo de Seguridad; reconocen que esa interpretación extensiva llevaría al unilateralismo, pero, no si titubeos, se inclinan a ver en la acción unilateral ciertas ventajas.

Los autores vislumbran la posibilidad de que se llegue a calificar jurídicamente la invasión de Irak; para ello se necesitaría que la Asamblea General de la ONU solicitara una opinión consultiva a la Corte Internacional de Justicia; reconocen que es muy difícil, nosotros diríamos imposible, que el Consejo de Seguridad haga tal solicitud, pues dos de los invasores tienen veto; también ven la dificultad de que los invasores aduzcan que se trata de una "controversia" que no pueda ser planteada dentro de las atribuciones "consultivas" del tribunal internacional; prevén igualmente la posibilidad de que el presidente del Consejo de Seguridad solicite una opinión al asesor jurídico del secretario general de la ONU y vaticinan litigios contra empresas que adquieran ventajas con la invasión.

Una afirmación de los autores que merece una transcripción; es la siguiente: "Ahora bien, si algo está claro es que si se admite la "legalidad" de la administración aliada establecida como resultado de esta guerra, no se podrá negar la "legalidad" de la guerra de la que trae causa". ${ }^{10}$

Curiosamente, en apoyo del párrafo transcrito citan al ministro francés de Relaciones Exteriores quien, después de expresar ex post facto el deseo de que la guerra, no apoyada por Francia, fuese breve e incruenta, en la medida de lo posible, hizo hincapié en: a) La necesidad imperiosa de preservar la unidad, la integridad y la soberanía de Irak, y b) En la 
responsabilidad de las fuerzas ocupantes. ${ }^{11}$ Vuelven los autores al argumento que pretende justificar la invasión por el incumplimiento de las condiciones del armisticio, que entendemos lo usan como sinónimo de "alto el fuego"; insisten en que el derecho internacional, dada la naturaleza provisional de esa tregua, permite la reanudación de las hostilidades cuando uno de los beligerantes viola las condiciones pactadas y se preguntan qué sentido tiene la institución del armisticio y cuál es su significado actual.

\section{CONCLUSIONES DE LOS AUTORES}

Concluyen los autores que el "arsenal" de resoluciones del Consejo de Seguridad sobre Irak habilitó legalmente a los invasores para emprender la guerra contra ese país; califican de débiles los argumentos que exigirían, después de reconocido el incumplimiento de Irak, que era necesaria una nueva resolución del Consejo de Seguridad que autorizara el uso de la fuerza; defienden, pero no aplican al caso, la argumentación por ellos descrita que justificaría la guerra en los principios de las Naciones Unidas o en la "legítima defensa preventiva" aduciendo que esos argumentos no han sido esgrimidos oficialmente por quienes invadieron Irak.

\section{RÉPLICA O ANTÍTESIS DEL AUTOR DEL PRESENTE ARTÍCULO}

\section{La autorización del uso de la fuerza mediante la Resolución 678 (1990) para restablecer la paz y la seguridad en la región}

Nos dicen los autores que, puesto que la Resolución 678 autorizó el uso de la fuerza armada, no sólo para lograr la expulsión de Irak, sino también "para restablecer la paz y la seguridad internacionales en la región", los Estados tuvieron en todo momento carta blanca o autoridad continua para reanudar las hostilidades hasta lograr el total restablecimiento de la paz y la seguridad internacionales en la región, a pesar de que el primer objetivo, el retiro de Irak, se logró con relativa facilidad por las fuerzas que apoyaron a Kuwait. 
El texto de la resolución nos fuerza a preguntarnos si ese segundo objetivo se incluyó teniendo en mente el propósito fundamental de la ONU del mantenimiento de la paz y seguridad internacionales, claro objetivo general de toda acción por el Consejo de Seguridad, o si en esa expresión se escondió una intención malévola para contar con excusas para hacer un uso de la fuerza unilateral y ulteriormente con propósitos de dominio sobre un Estado rico en petróleo.

A riesgo de pecar de ingenuos, supongamos que ese segundo objetivo se incluyó de buena fe para hacer referencia al propósito principal de la ONU y que fue más tarde que se buscó una interpretación amañada que no existía en la mente de los redactores de ese párrafo. Invitamos al lector a colocarse en el lugar de un representante de un Estado no miembro permanente del Consejo de Seguridad ¿Habría sospechado que esa referencia al más noble propósito de la ONU escondía la intención de dejar una puerta abierta para acciones bélicas ulteriores, no autorizadas por el Consejo de Seguridad? No nos dicen los autores que esa misma resolución exigió a los Estados que mantuvieran periódicamente informado al Consejo de Seguridad sobre sus acciones en apoyo de Kuwait, ni que el último párrafo resolutivo a la letra dice: "Decide mantener en examen la cuestión". A nuestro parecer, no hay base jurídica alguna para sostener que la referencia a ese segundo objetivo (el restablecimiento de la paz y la seguridad internacionales en la región) autorizó acciones no sancionadas por el Consejo de Seguridad, que por algo: a) Impuso la obligación de informarle sobre toda acción emprendida al amparo de esa resolución y b) Decidió "mantener en examen la cuestión", obviamente para el ejercicio de sus atribuciones en el ámbito del mantenimiento de la paz y la seguridad internacionales, que en modo alguno fueron delegadas. La interpretación de los autores nos parece absurda, pues con base en ella, todo Estado estaría autorizado por el Consejo de Seguridad de la ONU a intervenir unilateral y militarmente en esa explosiva región "para restablecer la paz y la seguridad internacionales" a su antojo. Es obvio que toda acción bélica ulterior al retiro de Irak requería la autorización expresa del Consejo de Seguridad, so pena de violar la más sacrosanta obligación de los Estados miembros de la ONU: la abstención de recurrir a la amenaza o al uso de la fuerza. El hecho de que se hayan dado acciones ulteriores no autorizadas expresamente por el Consejo de Seguridad no modifican la norma, tan solo la violan, sin afectar su validez jurídica. 


\section{Los efectos jurídicos del rompimiento de un acuerdo} del "alto el fuego" establecido por el Consejo de Seguridad de la $O N U$

El derecho internacional clásico reconocía que si los beligerantes llegaban a un acuerdo de "alto el fuego", y una de las partes violaba las condiciones de esa tregua, la otra tenía el derecho de reanudar las hostilidades. Los autores aducen, con razón, que el caso analizado debe estudiarse teniendo en mente todas las resoluciones pertinentes del Consejo de Seguridad. ¿Por qué entonces al esgrimir el argumento del armisticio no nos dicen que ese acuerdo se negoció y acordó en el seno del Consejo de Seguridad? ¿Por qué no nos dicen que el Consejo de Seguridad, en la resolución que fijó las condiciones del "alto el fuego" (Resolución 687), decidió seguir ocupándose de la cuestión? En esas circunstancias, es inadmisible pretender aplicar reglas que sí serían relevantes en un conflicto en el siglo XIX, principios del XX, o en cualquier conflicto actual no sometido al Consejo de Seguridad.

Obviamente, todo incumplimiento por Irak de las condiciones del "alto el fuego" fijadas por el Consejo de Seguridad de la ONU quedó en el marco de las atribuciones del consejo para evaluación y ulteriores decisiones. Luego entonces, el único efecto jurídico de una violación de las condiciones del "alto el fuego", determinadas por el Consejo de Seguridad, sería la nueva consideración del tema por ese órgano en descargo de sus responsabilidades, no el reinicio supuestamente lícito y automático de las hostilidades, como pretenden los autores, basándose en un derecho pre-Naciones Unidas, no aplicable al caso.

Es frecuente que juristas de la familia del common law, que veneran el precedente más que el código y que inducen las normas jurídicas de la práctica de los Estados, recurran, de buena o mala fe, al recurso de disminuir o a soslayar el código, aduciendo el mayor peso de la costumbre y la práctica de los Estados. En nuestra familia jurídica neorromanista, heredada de España, veneramos más al código que a la costumbre y sometemos ésta al texto escrito; deducimos normas de principios generales que creemos de validez universal y subsumimos el acto a la norma. ${ }^{12}$ No deja de sorprendernos que juristas españoles recurran, a la manera de sus

12 Véase Sweigert, Honrad y Kötz, Hein, Introducción al derecho comparado, México, Oxford University Press, 2002, pp. 273 y 274. 
correligionarios anglosajones, a precedentes clásicos de derecho internacional pre-ONU, que no toman en cuenta las atribuciones del Consejo de Seguridad en el caso estudiado, ni las resoluciones que ellos reconocen son el marco jurídico del tema.

\section{La relatividad de la obligación de no recurrir al uso} de la fuerza

Tal vez la parte más destructiva de la argumentación de los autores está en su afirmación de que la Carta de la ONU "no prohíbe la guerra de manera absoluta" y que tiene por objetivo el impedir la misma "en la mayor medida posible". De verdad nos cuesta trabajo entender tan negativa actitud. Es verdad que un vaso puede estar medio lleno o medio vacío, pero decir que porque la Carta de la ONU establece excepciones a la lapidaria prohibición de recurrir al uso de la fuerza armada, la disposición que marcó un hito en el derecho internacional público tiene tan sólo como tímido y titubeante objetivo impedir la guerra "en la mayor medida posible" es una afrenta a la más noble institución del derecho de gentes que nos legó fray Francisco de Vitoria y a las primeras palabras del Preámbulo de la Carta de la ONU sobre la determinación de los pueblos de preservar a las generaciones venideras del flagelo de la guerra.

\section{La supuesta tercera excepción a la prohibición de recurrir al uso de la fuerza sin autorización del Consejo de Seguridad}

No podemos dejar de comentar la supuesta "tercera excepción" sugerida por los autores a la prohibición de recurrir al uso de la fuerza, a saber: "el uso de la fuerza armada por causas humanitarias si el Consejo de Seguridad no actúa". Al respecto, tenemos que remitir a los autores a la publicación del Departamento de Información Pública de la ONU titulada "El ABC de las Naciones Unidas", la cual, al describir el debate que siguió a la controvertida cuestión de la intervención por razones humanitarias, planteada por el secretario general Kofi Annan, resume la posiciones de los Estados que apoyaron ese género de intervención, haciéndose hincapié en que, esos Estados aceptaron que, como último recurso, cabía proteger legítimamente los derechos humanos mediante el uso de la fuer- 
za autorizado por el Consejo de Seguridad. ${ }^{13}$ O sea, que el uso de la fuerza armada por causas humanitarias "si el Consejo de Seguridad no actúa", invocado por los autores está al margen del derecho y, cuando se ha practicado, ha sido en flagrante violación a la Carta de la ONU y en modo alguno lo aceptamos como norma jurídica in statu nascendi.

El Consejo de Seguridad puede encontrarse ante un caso de violaciones masivas y sistemáticas a los derechos humanos que, por ejemplo, por provocar migraciones transfronterizas igualmente masivas, pudiera calificarse de situación que amenace la paz y seguridad internacionales y que, por tanto, pudiera justificar la aplicación del capítulo VII de la carta relativo a "Acción en caso de amenazas a la paz, quebrantamientos a la paz o actos de agresión". Tratándose de situaciones locales, que por reprobables y lamentables que sean, no amenacen a la paz y seguridad internacionales, una actuación del Consejo de Seguridad que implique el uso de la fuerza pudiera calificarse de ultra vires, a menos de que se acepte que el consejo puede ejercer en nombre de la comunidad internacional una especie actio popularis, con base en la tesis que niega que una cuestión relativa a violaciones a los derechos humanos sea de la jurisdicción exclusiva del Estado en donde ocurre. ${ }^{14}$

\section{La "última oportunidad" dada a Irak por el Consejo de Seguridad}

y la amenaza de "graves consecuencias" hecha por ese órgano de la $O N U$

Respecto de la Resolución 1441 del Consejo de Seguridad, que advirtió a Irak que, de seguir infringiendo sus obligaciones, se expondría a "graves consecuencias”, los autores se preguntan: ¿Cuáles serían las graves consecuencias? Para ellos, la respuesta se encuentra en la Resolución 687 , o sea en la ruptura por Irak de las condiciones del "alto el fuego" y en la reanudación "lícita" de la guerra. Ya hemos refutado el supuesto derecho de reanudar las hostilidades a raíz de la violación por Irak de las condiciones del "alto el fuego". Concentrémonos ahora en la interpretación de la amenaza hecha por el Consejo de Seguridad respecto de las "graves consecuencias" que tendría el citado incumplimiento por Irak.

13 Publicación de la ONU, IBSN 92-1-3001184-3, p. 81.

14 Véase Gutiérrez Baylón, Juan de Dios, "Acciones ultra vires del Consejo de Seguridad y su responsabilidad derivada de la aquiescencia”, Anuario..., cit., pp. 369-409. 
Un problema de todo órgano colegiado es que, en aras de la unanimidad, sus miembros diluyen tanto el lenguaje que éste termina adoleciendo de una peligrosa ambigüedad; es el caso de la Resolución 1441. Hubiera sido mejor que el consejo hubiera amenazado a Irak que, de seguir violando sus obligaciones, el consejo determinaría qué medidas procedían, de conformidad con el capítulo VII de la carta, incluido el uso de la fuerza armada; obviamente, tal lenguaje no hubiera sido aceptable para el gobierno de los Estados Unidos de América, que ya había decidido ir a la guerra en violación del más solemne compromiso adquirido por ese Estado frente a la comunidad internacional y frente a sus propios ciudadanos al ratificar la Carta de la ONU. Así las cosas, los miembros del Consejo de Seguridad optaron por un lenguaje ambiguo que dio pie a una interpretación de mala fe: nos referimos a la tesis de la autorización implícita en la amenaza de las "graves consecuencias". De nada sirvió que las delegaciones de China, Francia y Rusia declararan que la Resolución 1441 excluía toda automaticidad en el uso de la fuerza, la ambigüedad fue utilizada por la coalición que invadió Irak en marzo de 2003. ${ }^{15}$ Nuevamente, los autores omiten recordar a sus lectores que la Resolución 1441 en su párrafo 14 decidió, no tácita, sino expresamente, "seguir ocupándose de la cuestión". Nos parece que tal decisión que, por cierto, se encuentra en todas las resoluciones del Consejo de Seguridad mencionadas por los autores, cierra la puerta a toda interpretación que sostenga que la invasión de Irak encuentra fundamento jurídico en la Resolución 1441 y en las anteriores.

A pesar de que el consejo decidió en la Resolución 1441 "seguir ocupándose de la cuestión", los autores insisten en que la tesis de sus oponentes (que califican de interpretación literal por exigir la determinación expresa de las "graves consecuencias") es inconsistente con la decisión del consejo de dar a Irak "la última oportunidad". Aducen que, de regresar el tema al consejo, pudiera no haber sido "la ultima oportunidad" por el riesgo de que ese órgano se paralizara con un veto, vaciándose de contenido todas la resoluciones anteriores. A ello respondemos que el consejo, no se negó a autorizar acciones en contra de Irak, tan sólo pidió, con su negativa a autorizar el uso de la fuerza en ese momento, se-

15 Véase "Research Paper 02/64, p. 24, del Parlamento del Reino Unido de la Gran Bretaña e Irlanda del Norte en la página de internet de ese Parlamento, o Reuter News, 9 de noviembre de 2002. 
gún las manifestaciones expresas de muchos de sus miembros permanentes y no permanentes, que se diera más tiempo a los inspectores para concluir con su cometido. Por otra parte, el veto que durante la guerra fría paralizó al consejo, tiene ahora una función que cumplir para detener ímpetus bélicos incontrolados de algunos gobernantes o por lo menos para dejar al margen de la ley a los transgresores que deciden actuar contra lo acordado por ellos en la Carta de la ONU.

El profesor sir Adam Roberts, quien sometió un memorándum a la Casa de los Comunes del Parlamento del Reino Unido para defender la tesis de la "autoridad continua" supuestamente investida por el Consejo de Seguridad en los invasores, es un ejemplo del jurista que parte de una posición política de su gobierno para construir argumentos a favor de la misma, en lugar de subsumir el caso al derecho aplicable, en busca de la verdad jurídica. ${ }^{16}$ No obstante, el profesor Roberts, en otro documento, expresó algunas dudas, pues comentó:

Han surgido problemas que incluyen la cuestión de qué consecuencias emanan de las violaciones por Irak: en particular, aún si EUA y socios tienen autoridad continua para usar la fuerza, queda la duda de si ello les da título válido para lanzar un ataque masivo para lograr un cambio en el gobierno. Además, la noción de 'autoridad continua' parece haberse minado por la dudosa calidad de la evidencia de que Irak aún posee armas de destrucción masiva en cantidades significativas. Algunos poco convincentes informes y presentaciones hechas antes de la guerra han debilitado el caso. Ha habido inevitablemente campo para desacuerdo respecto si fue atinado detener el sistema de verificación de la ONU que actuó en el marco de la Resolución 1441 a favor del uso de la fuerza, cuando los inspectores tenían posibilidad de visitar lugares en todo Irak y cuando el proceso de desarme había producido finalmente algunos resultados. Al cambiar las circunstancias después de la guerra, será posible "ex post facto" que otras justificaciones en pro del uso de la fuerza parezcan más convincentes [traducción del autor]. ${ }^{17}$

16 Véase House of Commons-Foreign Affaires-Written Evidence-Select Committee on Foreign Affaires Written Evidence-Memorandum from Professor Sir Adam Roberts-International Law and the Iraq War 2003. Página de internet http://www.publications.parliament.uk/cgi-bin/ukparl_hl? $D B=u k p a r l \& S T E M M E R=e n \& .$.

17 Véase Foreign Affaires Comité, Foreign Policy Aspects of the War against Terrorism, Tenth Repport, Session 2002-03, Hansard HC 405, para 91 (31 de julio de 2003). 
Nótese que aún aceptando la rebuscada y poco convincente tesis de la "autoridad continua", encontramos defensores que estiman que, con esa argumentación, se puede concluir que si hubo esa "autoridad continua", la misma fue utilizada ultra vires.

\section{La supuesta ilicitud del despliegue de fuerzas anterior a la invasión}

Reprochan los autores a los Estados y académicos que aducen la ilegalidad de la invasión su mutismo por el despliegue de fuerzas anteriores a la invasión que, según ellos, debió haber sido denunciado como violatorio de la prohibición de la amenaza del uso de la fuerza incorporado en el párrafo 4 del artículo 2 de la Carta de la ONU. Podemos replicar que el despliegue de fuerzas en alta mar o en el territorio de Estados que lo autorizan es lícito, sobre todo si el Consejo de Seguridad se prepara para actuar y es en apoyo de los inspectores del propio consejo; la ilicitud estuvo, no en los preparativos de una acción que pudo haber sido autorizada por el Consejo de Seguridad, sino en la acción unilateral de la coalición invasora respecto de una crisis que el consejo tenía aún en su agenda de trabajo; por otra parte, puede aducirse que el despliegue de fuerzas, en esas circunstancias, no atentaba contra la integridad territorial o la independencia política de Irak ni era incompatible con los propósitos de las Naciones Unidas, pues se esperaba que los Estados que se preparaban para actuar, lo habrían de hacer de conformidad con la Carta de la ONU y no en violación de la misma.

\section{Intervención militar en defensa de los Principios de las Naciones Unidas}

En su afán de encontrar argumentos en pro de la legalidad de la invasión, los autores se dejan llevar por ese imposible empeño hasta afirmar que se ha sostenido que es posible una intervención militar, aun sin estar prevista expresamente la posibilidad del uso de la fuerza en resolución alguna del Consejo de Seguridad, siempre y cuando la misma se haga para defender los principios consagrados en la Carta de las Naciones Unidas; recuerdan dos precedentes: la operación Zorro del Desierto contra Irak en 1998 y los bombardeos de la antigua Yugoslavia en 1999. Los mismos autores consideran más apropiado el segundo ejemplo. 
La acción militar en Kosovo por la OTAN no encuentra justificación en el derecho internacional actual. El texto de la Carta de la ONU es claro; en su artículo 53 se exige que toda medida coercitiva por organismos regionales se haga bajo la autoridad del Consejo de Seguridad. Se aduce que tal intervención fue en defensa de los Principios de las Naciones Unidas. ¿No es acaso un Principio fundamental de la ONU la proscripción del uso de la fuerza? ¿Podemos acaso dejar a la libre decisión de cada Estado cuándo la fuerza armada proscrita puede justificarse porque persigue la defensa de los propósitos y principios de la ONU? En nuestra opinión, tal tesis destruye todo lo acordado en 1945 en San Francisco respecto de los mecanismos para determinar cuándo es lícito el uso de la fuerza.

Las acciones militares de la OTAN en Kosovo y la invasión de Irak por EUA y aliados fueron seguidas de adopción de resoluciones por el Consejo de Seguridad de la ONU que establecieron mecanismos ex post facto para regularizar la situación y tratar de resolver la crisis. Así, la Resolución 1244 (1999) organizó la acción internacional, incluida la participación de la ONU, para tratar de paliar, entre otras cosas, la grave situación humanitaria en Kosovo. Es pertinente hacer notar que la Resolución 1244 no legalizó el uso de la fuerza por la OTAN que quedará para la historia como una violación de la Carta de la ONU por no haber mediado la necesaria autorización del Consejo de Seguridad para que la medida coercitiva del organismo regional fuera aplicada bajo su autoridad, como lo dispone el párrafo 1 del artículo 53 de la Carta de la ONU.

Una situación casi idéntica se dio tras la invasión de Irak. Efectivamente, ante un hecho consumado, el Consejo de Seguridad "legalizó" la ocupación de Irak por las potencias ocupantes mediante la Resolución 1483 (2003), de lo cual nos ocupamos en los párrafos que siguen.

\section{La legitimación por el Consejo de Seguridad de la ocupación} ¿significó la legalización de la invasión?

Cuando el secretario general de la ONU declaró veladamente la ilegalidad de la invasión, el presidente Bush reaccionó, según comentarios difundidos por la prensa internacional, diciendo que la invasión había recibido el visto bueno de la ONU, haciendo la misma interpretación que los autores, quienes en su artículo declaran que si se admite la legalidad 
de la ocupación, tiene que admitirse la "legalidad de la guerra que le trae causa". ${ }^{18}$ Aclaremos: toda ocupación mediante el uso de la fuerza, legal o violatoria del derecho internacional, trae aparejada la aplicación automática del derecho internacional humanitario de los conflictos armados. A esa rama del derecho no interesa quién fue el agresor y quién la víctima, tan solo le preocupa que los beligerantes cumplan con las responsabilidades que les da ese carácter.

El derecho internacional clásico reconocía como uno de los atributos del Estado el de hacer la guerra según sus propios criterios de seguridad nacional. ${ }^{19}$ Nótese la asombrosa similitud existente entre esa tesis superada por la Carta de la ONU y las tesis de quienes, como el presidente Bush y los autores, se esfuerzan por devolver a los Estados el poder de hacer la guerra a su libre arbitrio. Recordemos que cuando el secretario de Estado de la administración del presidente Bush se percató de que el Consejo de Seguridad no habría de autorizar la invasión de Irak antes de que terminara la labor de los inspectores designados por ese consejo declaró: "Estados Unidos se reserva el 'derecho', en tanto nación soberana, de utilizar la fuerza contra otro país que ya ha sido advertido". ${ }^{20} \mathrm{Si}$ el Estado tenía antaño esa facultad para decidir la guerra y la paz, era lógico que se reconociera al vencedor que ocupaba el territorio del enemigo la potestad de ejercer una autoridad que entonces se consideraba lícita y de iure, aun cuando el ocupante hubiera sido agresor.

Después de la Carta de la ONU, a raíz de la proscripción del uso de la fuerza, el Estado que ocupa un territorio en violación de la Carta de la ONU tiene la autoridad de facto que le da su poderío militar, pero la ilegalidad de su acto afecta su autoridad, que con buena lógica, no puede considerarse de iure. Cuestión aparte son las obligaciones o responsabilidades del ocupante, sin importar si su ocupación militar es conforme a derecho, o en violación del mismo.

Si preguntáramos a los juristas que defienden la legalidad de la ocupación de Irak por Estados Unidos de América y aliados si estarían dispuestos a reconocer que el ejército de Saddam Hussein tuvo autoridad de iure durante el tiempo que ocupó Kuwait, seguramente recibiríamos como respuesta un rotundo "no". ¿Por qué entonces el Consejo de Segu-

18 Véase supra transcripción en la apartado VI del presente artículo.

19 Véase Nguyen Quoc, Dinh, Droit International Public, 7a. ed., París, LGDJ, 2002, p. 935 (De la liberté de faire la guerre).

20 Véase Reforma, México, 28 de enero de 2003, p. 22-A. 
ridad de la ONU en la Resolución 1483 (2003), que legalizó, nos guste o no, la ocupación de Irak (no la invasión), reconoció en un párrafo preambular que, "en virtud del derecho internacional aplicable" las potencias ocupantes ejercían autoridad?

No reprochamos a ese consejo que haya legalizado la ocupación ante un hecho consumado, con el noble fin de involucrar a la ONU en la tarea de reconstrucción y vigilar los actos de los ocupantes; le reprochamos que haya afirmado con criterio decimonónico que el derecho internacional reconoce automáticamente, como lo hacía antaño, la autoridad de un ocupante agresor. Felizmente el Consejo de Seguridad por ser órgano político no sienta jurisprudencia y esa afirmación errónea del párrafo preambular citado no pasará a los anales del derecho. Aclaremos: reconocemos que el Consejo de Seguridad sí tuvo, en virtud de sus atribuciones, autoridad para reconocer como acto político la autoridad de facto de las potencias ocupantes, pero no de iure "en virtud del derecho internacional aplicable".

Vayamos ahora a la afirmación de los autores, quienes sostienen que si se admite la legalidad de la ocupación, tiene que admitirse la "legalidad de la guerra que le trae causa". Ya admitimos que la ocupación ilegal de Irak fue legalizada ex post facto por una decisión política del Consejo de Seguridad, adoptada para involucrar a la ONU en la reconstrucción de Irak y controlar la conducta de los agresores. El hecho de que la invasión de Irak no haya sido condenada por el Consejo de Seguridad, no significa la legalidad de la misma. ¿Cómo iba a condenar ese órgano la invasión si dos de sus miembros permanentes fueron invasores?

Sí resulta inexplicable que los Estados árabes no hayan propuesto la convocatoria de un período extraordinario de sesiones de la Asamblea General de la ONU para considerar la invasión. Es fácil imaginar la enorme presión de la poderosa maquinaria estadounidense en todos los Estados miembros de la ONU para impedir una reunión del órgano plenario que hubiera podido, por mayoría de votos, condenar la agresión. Además se hubiera aducido, tal vez con razón, que el asunto estaba bajo consideración por el Consejo de Seguridad, lo cual, según la carta, bloquea la posibilidad de que la asamblea se ocupe del tema.

Si se aceptan los argumentos de esta réplica o antítesis contra la tesis de la "automaticidad" de la renovación de la resolución que autorizó el uso de la fuerza contra Irak y contra el "derecho" de reanudar hostilidades por violación de las condiciones del "alto el fuego", es fácil aceptar 
la dicotomía que niegan los autores, es decir, el reconocimiento de la legalización de la ocupación por el Consejo de Seguridad y la afirmación de que la invasión de marzo de 2003 fue violatoria de la Carta de la ONU.

A mayor abundamiento, recordemos la Declaración sobre los Principios del Derecho Internacional referentes a las relaciones de amistad y a la cooperación entre los Estados, de conformidad con la Carta de las Naciones Unidas, adoptada solemnemente por la Asamblea General del la ONU durante la celebración de el vigésimo quinto aniversario de su fundación, mediante la Resolución 2625 (XXV). En esa Declaración, redactada como corolarios de los Principios de las Naciones Unidas por notables juristas designados por sus gobiernos se expresó:

Una guerra de agresión constituye un crimen contra la paz, que, con arreglo al derecho internacional, entraña responsabilidad.

El territorio de un Estado no será objeto de ocupación militar derivada del uso de la fuerza en contravención de las disposiciones de la Carta [de la $\mathrm{ONU}]$.

$\mathrm{Si}$, como creemos, la invasión fue ilegal, la legalización de la ocupación por el Consejo de Seguridad deja abierta la posibilidad de que, con las limitaciones de que adolecen los tribunales internacionales, en algún momento se declare, al menos como opinión consultiva, la ilegalidad de la invasión.

En apoyo de nuestra tesis podemos citar el principio de validez universal incorporado en el artículo 1 del proyecto de artículos sobre responsabilidad internacional de la Comisión de Derecho Internacional que a la letra dice: "Todo hecho internacionalmente ilícito del Estado genera su responsabilidad internacional". ${ }^{21}$

\section{La cuestión de la legítima defensa preventiva ${ }^{22}$}

Si bien los autores nos recuerdan que los invasores no adujeron la "doctrina" de la legítima defensa preventiva del presidente Bush, ampliamente difundida por la prensa internacional, sí ven ellos considerables

21 Véase resolución de la AGNU 56/83.

22 Véase Gros Espiell, Héctor, "La pretendida legítima defensa preventiva y la guerra en Iraq", Anuario..., cit., pp. 189-204. 
ventajas en una interpretación amplia de la noción de legítima defensa reconocida en la Carta de la ONU. Recordemos la primera parte del artículo 51 de la Carta de las Naciones Unidas, que seguramente muchos de los lectores saben de memoria: "Ninguna disposición de esta Carta menoscabará el derecho inmanente de legítima defensa, individual o colectiva, en caso de ataque armado contra un miembro de las Naciones Unidas, hasta tanto que el Consejo de Seguridad haya tomado las medidas necesarias para mantener la paz y la seguridad internacionales".

Hay acuerdo entre los juristas respecto del carácter de la norma que la Carta de la ONU codificó en ese artículo. Las palabras derecho inmanente claramente indican que ese derecho ya existía como costumbre desde antes de la carta. Pueden darse dos explicaciones: la primera, que esa facultad de auto-ayuda existía confundida con el derecho de los Estados soberanos de hacer la guerra y de defenderse de conformidad con su propio criterio, sin limitación alguna y la segunda que, a raíz de las restricciones a la legitimidad del recurso a la guerra, iniciadas con la creación de la Sociedad de las Naciones, la legítima defensa nació como un derecho "inmanente" reconocido por una opinio iuris universal. ${ }^{23}$

Se llega así a la Carta de las Naciones Unidas y se redacta el artículo 51 que restringe el derecho consuetudinario existente con las palabras en caso de ataque armado. La maldad, que no ha desaparecido de la mente del ser humano y que sólo la cultura jurídica y moral habrá de aminorar, hizo que crisis y agresiones pusieran muy pronto a prueba el artículo 51 transcrito y que tanto los gobiernos como los estudiosos del derecho internacional plantearan dos vertientes principales de interpretación de esa norma:

1. La primera, que sostiene que el derecho consuetudinario coexiste con el artículo 51, interpreta la restricción incorporada en las palabras en caso de ataque armado de una manera tan amplia que la hace virtualmente inexistente.

2. La segunda, que reconoce que el derecho a la legítima defensa fue acotado por la redacción de la Carta de la ONU y por el acuerdo incorporado en ella, insiste en que sin ataque armado no hay derecho a la legítima defensa.

23 Véase Cot, Jean Pierre y Pellet, Alain, La Charte des Nations Unies, 2a. ed. rev. y aum., Económica, pp. 772 y 793. 
Nos parece que la primera vertiente es incompatible con las reglas para la interpretación de los tratados acodadas en la Convención de Viena sobre el Derecho de los Tratados de $1969 .{ }^{24}$ Si según esas reglas un tratado deberá interpretarse de buena fe conforme al sentido corriente que haya de atribuirse a los términos del tratado en el contexto de éstos $y$ teniendo en cuenta su objeto y fin, resulta evidente que "ataque armado" no puede significar "amenaza". Siendo el propósito principal de la ONU preservar a las generaciones venideras del flagelo de la guerra, la interpretación restrictiva parece imponerse.

Quienes nos inclinamos por la interpretación restrictiva de la segunda vertiente, nos encontramos ante un problema: ¿Obliga el artículo 51 de la carta a esperar a que se inicien las hostilidades para ejercer la legítima defensa? ¿Habrá sido la intención de los redactores de la carta colocar a las víctimas potenciales de un ataque en tal estado de indefensión? Analicemos una hipótesis que nos ayuda a dilucidar el problema: cuando ocurrió el ataque armado de Japón contra Pearl Harbor, si hubiera estado en vigor la Carta de la ONU y si los servicios de inteligencia de Estados Unidos de América hubieran sido eficientes, ¿hubiera tenido la fuerza aérea estadounidense el derecho de interceptar la flota aérea de guerra japonesa en alta mar? Ciertamente sí, porque se enfrentaba a un ataque armado real, en progreso, no en potencia.

Cuando en 1967, ante la movilización del ejército de Egipto y el bloqueo de un puerto, Israel lanzó su fuerza aérea contra las posiciones egipcias antes de que invadieran Israel, ¿ejerció el derecho de legítima defensa reconocido en la Carta de la ONU? Nos parece que debemos responder en sentido afirmativo. Nos encontramos pues frente un ejemplo histórico en el que se puede reconocer que se dio un ataque armado, aun cuando quien ejerció la legítima defensa no había aún sufrido la agresión dentro de sus fronteras. Es entonces posible sostener que las figuras de la legítima defensa anticipada o, peor aún, la preventiva, no son necesarias si la expresión ataque armado se interpreta con una lógica flexible para incluir actos agresivos inmediatamente anteriores al inicio de las hostilidades propiamente dichas. Si a eso se le llama legítima defensa "anticipada" por la inminencia del ataque, la inmediatez de la respuesta y la clara intención de limitar la respuesta al rechazo de la agresión, no tenemos problema. 
Nos parece que hacer prevalecer el derecho consuetudinario sobre la Carta de la ONU es contrario a la letra y al espíritu de la norma. Creemos que la legítima "defensa preventiva", existente en la política de los EUA, pero ausente en el derecho internacional, puede llevar a actos como el ataque israelí de 1981 para destruir un reactor nuclear en Irak, condenable y violatorio del derecho internacional, pero al menos basado en la existencia de un instrumento capaz de producir armas nucleares; peor aún, puede servir de pretexto para iniciar una guerra como la que sufre Irak, basada en sospechas y mentiras ya comprobadas por la ausencia de armas de destrucción masiva. Lo más grave de la situación actual es que el presidente Bush y el primer ministro Blair han olvidado los ideales promovidos por Roosvelt y Churchil en la Carta del Atlántico suscrita el 14 de agosto de 1941 para suprimir, de entre los recursos lícitos para resolver controversias internacionales, el uso de la fuerza. ${ }^{25}$

La guerra fría y la consiguiente parálisis del Consejo de Seguridad, obligó a juristas a elaborar doctrinas a partir de la total ineficacia del Consejo de Seguridad. Pero ahora que es posible aspirar a una cooperación entre los miembros permanentes del Consejo de Seguridad, es lamentable que la administración del presidente Bush haya desarrollado "doctrinas" políticas que pretenden destruir el sistema de la ONU y fortalecen un unilateralismo que da peligrosas armas políticas a todo Estado que opte por el ese medio en prevención de ataques imaginarios.

La prevención puede ser necesaria y no debemos olvidar que el Consejo de Seguridad sí puede, en ejercicio de sus atribuciones, lanzar o autorizar un ataque preventivo si llega a la conclusión de que el mismo es necesario para desarmar a un potencial agresor renuente a someterse a controles internacionales establecidos por el mismo consejo u otra organización competente, o para impedir el apoyo a organizaciones terroristas, todo ello para lograr el objetivo común de preservar la paz y la seguridad internacionales. ${ }^{26}$ En relación con otra crisis, sostenemos que el Consejo de Seguridad hizo mal en invocar la legítima defensa al autorizar con términos ambiguos la invasión de Afganistán. Ocurrido el artero ataque a la población civil el 11 de septiembre de 2001 en Nueva York y en el pentágono contra militares no combatientes y población civil, no 
había ya ataque que rechazar, el mismo había sido consumado, y por tanto no había legítima defensa que ejercer; lo que ocurrió fue una autorización del Consejo de Seguridad para actuar contra los criminales mediante una acción que estuvo lejos de ser inmediata, como lo exige la lógica de la legítima defensa. Fue la resolución del Consejo de Seguridad y no la institución de la legítima defensa la base jurídica de la invasión de Afganistán. Otra cuestión es si los medios empleados fueron atinados políticamente, si el Consejo de Seguridad respondió a un "estado de necesidad" y si en esa invasión se cumplió con el derecho internacional humanitario aplicable a los conflictos armados.

La posición oficial del Reino Unido fue que la amenaza de Saddam Hussein era seria y actual, más que inmediata o inminente, si bien se basó en información falsa sobre la existencia de armas de destrucción en masa. ${ }^{27}$ El Reino Unido percibió peligros en la amplia interpretación de la legítima defensa hecha por EUA, si bien sostuvo que el derecho internacional debe evolucionar para hacer frente a nuevos retos tales como la amenaza terrorista. Con razón, círculos británicos temieron que la mal llamada doctrina Bush, porque ha sido una constante en la política estadounidense, era un riesgo serio que legitimaría un uso de la fuerza agresivo por otros Estados "menos respetuosos del derecho".

La respuesta oficial del Reino Unido a la a Estrategia de Seguridad Nacional del presidente Bush fue en los siguientes términos:

Está bien establecido en derecho internacional que el derecho de adoptar acciones militares necesarias y proporcionales en legítima defensa se aplica no sólo cuando un ataque ha ocurrido sino también preventivamente cuando un ataque es inminente. El Gobierno apoya el punto de vista que sostiene que ese derecho se aplica tanto a amenazas del terrorismo como a las amenazas más convencionales del pasado. La posición consistente del Reino Unido ha sido que nosotros sólo iniciaremos acciones militares en esas circunstancias y como último recurso. El Gobierno no ha considerado necesario reconsiderar su política en esta materia a raíz de la publicación del documento de los Estados Unidos [traducción del autor]. ${ }^{28}$

27 Véase McGoldrick, Dominic, From '9-11'to the 'Iraq war 2003, International Law in an age of complexity, Oxford and Portland Oregon, Hart Publishing, 2004, pp. 73-76; 4.4.3 The UK and Pre-emptive Self-Defence.

28 Véase idem. 
Salta a la vista la incompatibilidad de esa posición con la complicidad del Gobierno del Reino Unido con la prisa de Washington por invadir Irak cuando progresaban y parecían acercarse a buen fin las inspecciones del equipo de la ONU presidido por el veraz sueco Hans Blix. Desde luego la invasión de Irak no fue un último recurso.

En los medios británicos se ha sugerido "que el documento de EUA puede ser leído de manera consistente con el derecho internacional" y que el Reino Unido prefiere que la "doctrina Bush" se aplique previa determinación por el Consejo de Seguridad de que las acciones del Estado señalado representan una amenaza a la paz y a la seguridad internacionales. En nuestra opinión, tal tesis no es compatible con el derecho internacional porque no basta esa determinación del consejo, se requiere su autorización expresa. Reconocemos, no obstante, la buena intención de condicionar los ímpetus de los halcones estadounidenses con una determinación previa por el Consejo de Seguridad. Insistimos en que tal tesis es incompatible con el derecho internacional porque, según la Carta de la ONU, no basta con que el Consejo de Seguridad determine, en cumplimiento de sus atribuciones, que un determinado Estado representa una amenaza a la paz y seguridad internacionales. Para que el uso de la fuerza armada contra esa amenaza sea conforme a derecho, se requiere una autorización inequívoca y expresa del Consejo de Seguridad. Vemos en esa tesis un vano esfuerzo por justificar en derecho la invasión de Irak, pues las advertencias y exhortaciones a Irak por el consejo, no autorizaron la invasión que EUA, Reino Unido y aliados llevaron a cabo en violación de la Carta de la ONU. ${ }^{29}$

En fin, en el llamado "'mundo civilizado" felizmente hay desacuerdo respecto de la "doctrina Bush". Tenemos tesis que van desde la afirmación (hoy desacreditada por los hechos) de que el verdadero casus belli de la agresión a Irak fue la prevención de un ataque que Saddam Husein hubiera podido lanzar contra EUA, ${ }^{30}$ hasta la descalificación de esa "doctrina" como inconsistente con el orden jurídico post-1945; así Al Gore declaró: "Lo que esta doctrina hace es destruir el objetivo de un mundo en el que los Estados se consideran sometidos al derecho, particularmente en el ámbito de las normas para el uso de la violencia. Ese concepto

29 Véase McGoldrick, Dominic, op. cit., p. 74.

30 Véase Howard, M., "The Bush doctrine: it's a Brutal World, so Act Brutally", The Sunday Times, 23 de marxo de 2003, citado por McGoldrick, op. cit., p. 76. 
sería sustituido por la noción de que no hay derecho sino la discreción del presidente de los Estados Unidos de América [traducción del aut tor]". 31

10. Consideración de algunos de los criterios contenidos en el informe del Grupo de Alto Nivel designado por el secretario general de la ONU, titulado: Un mundo más seguro: la responsabilidad que compartimos

A mayor abundamiento, consideremos el informe del Grupo de Alto Nivel convocado por el secretario general de las Naciones Unidas para asesorarlo en los temas concernientes a la reforma de la organización (en adelante "el grupo"). El informe del grupo contiene una parte IX titulada "El uso de la fuerza: normas y directrices". ${ }^{32}$ En esa parte el grupo, después de expresar la aspiración de la comunidad internacional, concluida la guerra fría, de contar con un sistema internacional que se rija por el imperio de la ley, nos plantea tres cuestiones que, según el grupo, en la práctica se presentan como particularmente difíciles:

- La del Estado que aduce el derecho a recurrir a la fuerza a título preventivo, en legítima defensa, en atención a una amenaza que no es inminente.

- La del Estado que parece estar planteando una amenaza externa, real o posible, a otros Estados o pueblos más allá de sus fronteras, pero no hay acuerdo en el Consejo de Seguridad acerca de cómo reaccionar, y

- La de la amenaza de índole primordialmente interna, para la propia población de un Estado.

El grupo concluye que cuando la amenaza de agresión es inminente el derecho internacional faculta al Estado amenazado a actuar, si no hay otro medio para impedir la agresión y la defensa es proporcional. Por otra parte, al considerar la amenaza "no inminente" (así fue la supuesta amenaza del Irak de Sadam Hussein) el grupo concluye que el Estado que se siente amenazado debe recurrir al Consejo de Seguridad; en otras

31 Véase Gore, Al, “Against a Doctrine of Pre-Emptive War”, Iraq War Reader, citado por McGoldrick, op. cit., p. 76.

32 Véase documento de la Asamblea General de la ONU A/59/565. 
palabras niega el derecho a la defensa preventiva sin la autorización del Consejo de Seguridad y se niega a aceptar la legitimidad de la acción preventiva unilateral. ${ }^{33}$ Concluye el grupo con la siguiente lapidaria afirmación: "No somos partidarios de modificar el texto ni la interpretación del artículo 51 [de la Carta de la ONU]".

Respecto del Estado que representa una amenaza para terceros, el grupo concluye: "El Consejo de Seguridad tiene plenas facultades en virtud del capítulo VII de la Carta de las Naciones Unidas para hacer frente a las diversas amenazas a la seguridad que preocupan a los Estados. La tarea no consiste en encontrar alternativas al Consejo de Seguridad como fuente de autoridad sino en hacer que funcione mejor que hasta ahora". ${ }^{34}$

En cuanto a la amenaza de índole interna para la población de un Estado, el grupo afirma:

Aprobamos la norma que se está imponiendo en el sentido de que existe una responsabilidad internacional colectiva de proteger, que el Consejo de Seguridad puede ejercer autorizando la intervención militar como último recurso en caso de genocidio y otras matanzas en gran escala, de depuración étnica o de graves infracciones del derecho internacional humanitario que un gobierno soberano no haya podido o no haya querido prevenir. ${ }^{35}$

Una valiosa aportación del grupo son los criterios para determinar cuando una acción autorizada, además de ser legal en virtud de las atribuciones del Consejo de Seguridad, es legítima. Esos criterios que el grupo recomienda sean utilizados por el consejo al debatir si se ha de autorizar o aprobar la fuerza militar, son los siguientes:

a) Gravedad de la amenaza. La amenaza de daño a la seguridad del Estado o del ser humano, ¿es de índole tal y es suficientemente clara y grave como para justificar a primera vista el uso de la fuerza militar? En el caso de las amenazas internas, reales o que se consideren inminentes, ¿entrañan genocidio u otras matanzas en gran escala, actos de depuración étnica o infracciones graves del derecho internacional humanitario?

b) Propósito correcto. ¿Queda de manifiesto que el objetivo primordial de la acción militar que se propone consiste en poner fin a la amena-

35 Véanse párrafos 199 a 203 del documento citado $\mathrm{A} / 59 / 565$. 
za o evitarla, cualesquiera que sean los demás motivos o propósitos que estén en juego?

c) Último recurso. ¿Se han considerado todas las demás opciones no militares para hacer frente a la amenaza y hay fundamentos razonables para creer que no arrojarán resultados?

d) Proporcionalidad de los medios. La escala, la duración y la intensidad de la acción militar que se propone ¿constituyen el mínimo necesario para hacer frente a la amenaza?

e) Balance de las consecuencias. ¿Hay posibilidades razonables de que la acción militar logre hacer desaparecer la amenaza sin que sus consecuencias sean peores que las de no hacer nada?

No aceptamos que la invasión de Irak haya sido conforme a derecho como afirman los autores, pero aún en la hipótesis de que tuvieran razón o de que el Consejo de Seguridad hubiera autorizado esa acción bélica, con los criterios del grupo para evaluar la legitimidad de la acción constataríamos que: a) La amenaza de Sadam Hussein fue una falacia por la inexistencia ya comprobada de armas de destrucción masiva; b) Que el propósito estará siempre manchado por los intereses petroleros y de interés de dominio espurio en la región; c) Que en modo alguno fue el último recurso para poner orden en el desorden que representaba Sadam Hussein; d) Que no hubo proporcionalidad en los medios pues por mucho que se pudiera justificar en términos políticos la necesidad de neutralizar al régimen dictatorial de Irak, no fue proporcional la invasión y ocupación de un Estado, y e) En cuanto al balance de las consecuencias, ya se cuentan en cientos de miles las víctimas civiles inocentes.

\section{CONCLUSIONES}

1. La Resolución 678 que autorizó el uso de la fuerza armada para expulsar a Irak de Kuwait no autorizó "autoridad continua" alguna para lograr el segundo objetivo mencionado, a saber: "el restablecimiento la paz y la seguridad internacionales en la región". Nos parece que ese segundo objetivo fue mencionado como un propósito general de las Naciones Unidas en todas las actuaciones del Consejo de Seguridad y que interpretarlo como una carta blanca para usar la fuerza sine die en una región que probablemente no logrará la paz en varios lustros, es una interpretación dolosa y absurda. Además, el Consejo de Seguridad en todas las resoluciones sobre el tema expresó su voluntad de mantener la cues- 
tión en su agenda o programa de trabajo, lo cual bloquea, en buena lógica, toda interpretación respecto de una supuesta "autoridad continua", de automaticidad o de autorizaciones implícitas.

2. Aceptamos que Irak violó las condiciones del "alto el fuego" acordado en el seno del Consejo de Seguridad y que, según el derecho internacional clásico, una violación del armisticio da derecho, en caso de urgencia, a reanudar las hostilidades. No obstante creemos que esa norma no es aplicable al caso de Irak porque el "alto el fuego" fue acordado en el Consejo de Seguridad que mantuvo explícitamente el tema en su agenda o programa de trabajo. Luego entonces, conforme al derecho incorporado en la Carta de las Naciones Unidas, las partes requerían una autorización del Consejo de Seguridad para reanudar hostilidades.

3. No existe una tercera excepción a la lapidaria prohibición de recurrir a la amenaza o al uso de la fuerza para actuar unilateralmente en terceros Estados cuando se dan violaciones masivas a los derechos humanos. El Consejo de Seguridad de la ONU puede, en ejercicio de sus atribuciones, autorizar el uso de la fuerza para intervenir en un Estado si la situación interna, incluidas las violaciones masivas a los derechos humanos, a juicio del consejo, ponen en peligro la paz y la seguridad internacionales. En esos y otros casos existe siempre el peligro de que el consejo actúe ultra vires, por lo que el uso de la fuerza armada debe ser siempre el último recurso y, salvo el caso de la legítima defensa, el uso de la fuerza armada para ser conforme a derecho requiere de autorización expresa del Consejo de Seguridad y no debe usarse de manera unilateral ni por coaliciones no sancionadas por el Consejo de Seguridad.

4. A pesar de que el Consejo de Seguridad advirtió en la Resolución 1441 que, de seguir infringiendo sus obligaciones, "se expondría a graves consecuencias" y de que el consejo también advirtió que sería "la última oportunidad", nuevamente, en virtud de las disposiciones de la Carta de la ONU, que reconoce al consejo el monopolio para decidir cuándo se puede recurrir al uso de la fuerza, salvo el caso ya mencionado de la legítima defensa, la invasión de Irak fue una violación de la Carta, en virtud de que el consejo no autorizó esa medida y de que no delegó atribución alguna al expresar su firme decisión de "seguir ocupándose de la cuestión".

5. La legitimación de la ocupación de facto hecha por el Consejo de Seguridad fue una decisión política adoptada con la mira de permitir a la ONU su participación en la reconstrucción de Irak y con el ánimo de 
ejercer algún dominio en la situación. La autoridad de los ocupantes que emana de esa resolución es, por definición, provisional y está limitada a la prestación de asistencia y protección en la situación de emergencia generada por la guerra, salvo las acciones que expresamente autorice el Consejo de Seguridad. El derecho internacional no reconoce autoridad de iure a una potencia invasora que ocupa un territorio en violación del derecho internacional. El derecho internacional humanitario aplicable a los conflictos armados impone responsabilidades a todos los beligerantes, incluidos los ocupantes, con independencia de que sean agresores o víctimas.

6. La legalización por el Consejo de Seguridad de la ocupación de Irak por los invasores-agresores no significó la legalización de la invasión de marzo de 2003, la cual queda para los anales de la historia como un crimen contra la paz que, con arreglo al derecho internacional entraña responsabilidad.

7. La "legítima defensa preventiva", aducida por el presidente Bush como política de su administración, no tiene fundamento en el derecho internacional. La supuesta amenaza que Irak representaba para los invasores fue desmentida por la ausencia de armas de destrucción en masa y la invasión no puede adecuarse a la figura de la legítima defensa incorporada en el artículo 51 de la Carta de la ONU, aún aceptando las doctrinas que permiten alguna anticipación, antes de las hostilidades.

8. Los criterios para determinar la legitimidad de una acción militar aprobada por el Consejo de Seguridad de la ONU, recomendados por el Grupo de Alto Nivel designado por el secretario general de la ONU para asesorarlo es asuntos concernientes a la reforma de las Naciones Unidas, aplicados a la invasión ilegal de Irak, muestran que no se dieron los requisitos de gravedad de la amenaza; propósito correcto; último recurso, ni proporcionalidad de los medios y que el balance de las consecuencias confirma la ilegitimidad de la acción. 